Sharaf N. Rehman

University of Texas Rio Grande Valley

Department of Communication

e-mail: sharaf.rehman@utrgv.edu

\title{
A camera never told the truth: An exploration of objectivity in photojournalism
}

\begin{abstract}
Several cases have surfaced in the past two decades where the photojournalists associated with some of the most respected and trusted news organizations have been accused of altering the news photos. During the same time, the developments in the digital cameras and editing software have put the image altering technology into the hands of all practicing journalists and journalism students. This paper explores two, somewhat connected, issues: objectivity in photojournalism and ethics of altering photographic images. The paper discusses objectivity in journalism in general and photojournalism to address the question: Can a photojournalist use a camera to record reality in an objective manner? Since the photographers have altered (retouched) images from the very beginning of photography, where are the ethical boundaries of image alteration for the photojournalists?
\end{abstract}

Keywords: objectivity in news reporting, development of photography, war photography, image alteration, Photography and political propaganda

JEL Classification: Z1, Z13

\section{Introduction}

A picture appeared on the Internet on May 2, 2011, showing the dead body of Osama Bin Laden. It was an altered image. An archived picture of his face was pasted onto some other person's body. The composite picture "has become an iconic image of the dead Al-Qaeda leader" (Davis, 2012). 
In 2002, a Pulitzer-Prize winning photographer, Edward Keating photographed a boy, Brandon Benzo, pointing a toy gun at a camera. The boy stood outside a store where the FBI had apprehended six alleged Al-Qaeda operatives. The picture appeared in The New York Times and several other publications. The Arab-American readers complained that the picture reinforced an anti-Muslim bias and stereotyped the Arabs as teaching violence to their children. Keating had staged the picture by asking the boy to point the gun into his camera (Pullman, 2017).

On June 27, 1994, Newsweek carried a picture of O. J. Simpson on its cover. The picture was obtained from the police department. Newsweek ran the picture without any digital maneuvering. The Time magazine darkened the skin in the mug shot, reduced the clarity, and added a growth of facial stubble. The effect was sinister (Davis, 2012).

Arnold Crane is a world-famous photographer. His works are exhibited at some of the most prestigious museums in the world-New York Metropolitan and the Museum of Modern Art among them. Crane contends that once a picture is digitally altered it's no longer a news picture; it becomes an illustration. "Some alterations are all right," Crane adds. "You can remove an obscuring highlight or a reflection in a window, but you can't remove an object. And you can't change the meaning of a photograph. [...] I took a picture of a woman and (digitally) removed a zit from her face. That's where I draw the line" (Davis, 2012).

This paper explores the fine line between producing an illustration to sell a product and shooting a news photo. The paradox of photojournalism is that the photograph is the nexus of objectivity and subjectivity. A photograph itself is an object, but its creation is subjective. Historically, journalists and reporters are held accountable to the professional and ethical standards of their organizations. Newspaper editors and the gatekeepers at the news agencies insist on impartiality, fairness, and accuracy.

Journalistic objectivity demands disinterestedness, factuality, and nonpartisanship. These were the fundamental criteria of the American journalism and the media. ${ }^{1}$

Objectivity in journalism is necessary because providing the facts allows the readers/viewers to make up their own mind about a story and arrive at their own interpretations. To this end, the journalists should present the facts even if they disagree or dislike those facts. Objective reporting, as a rule, is the reporting and portraying the issues and events in a neutral and unbiased manner, regardless of the journalist's opinion and beliefs.

The four major global news agencies: Agence France-Presse (AFP), Associated Press (AP), Reuters and Agencia EFE, follow a basic philosophy of providing a single objective news feed to all their subscribers, i.e., they do not provide separate feeds for conservative or liberal news outlets. Similar rules and rigor are applied to photojournalism. Altering a photographic image to change the story is unacceptable. If a photographer is caught changing the emphasis or the focus of

\footnotetext{
${ }^{1}$ When this author refers to "the media," it includes the major newspapers, well-known Internet sites, print magazines, and national TV and radio news networks.
} 
a photograph they can lose their job. Many photographers in recent years have. But only if and when they are caught. The publisher of the American Conservative, Ron Unz observed,

For decades, I have closely read the New York Times, the Wall Street Journal, and one or two other major newspapers every morning, supplemented by a wide variety of weekly or monthly opinion magazines. Their biases in certain areas had always been apparent to me. But I felt confident that by comparing and contrasting the claims of these different publications and applying some common sense, I could obtain a reasonably accurate version of reality. I was mistaken. (2013, p. 11)

The conclusion reached by Unz is unsettling. It implies that the careless and the unethical behavior of the American media leaves its consumer without an accurate picture of reality or truth. In recent years, two major developments have taken place that put journalistic objectivity in jeopardy. One of these is financial, and the other, technological.

\section{New media constraints}

Due to the advertising revenues being diverted to the Internet, all major newspapers and television networks have made cuts in their news operations. The number of international correspondents and reporters that reported from the capital cities of the world has shrunk. Instead, the news agencies and news outlets rely on freelance writers and photojournalist. Since there is competition among the freelance reporters and photographers, the speed at which a story is delivered, or a picture is submitted is more important than the accuracy of the facts or the authenticity of a photograph. As a result, there have been countless instances where the media either got the stories wrong or missed the important stories altogether (Friedersdorf, 2013), consequently, the credibility of the American media is at its lowest (Swift, 2017). A majority of the under-30 years of age are accessing the news on their smartphones, i.e., from the Internet sources that do not follow the factchecking practices of the traditional print and broadcast media. The audiences are getting different versions of the truth from different sources.

It was not too many years ago that a reporter would submit a story and the editors would check it for facts and accuracy to make sure that the figures were correct, the exact words were attributed to the speakers, and that people's name and titles were carefully checked and correctly spelled. Tracking down witnesses and interviewing people to obtain, check, and verify the facts was hard work. It took, dedication, tenacity, and time. Stories were often rewritten and edited by the editors. The reporters, in a sense, lost control of their story once it was handed over to the paper or the magazine. 
As a photographer covering a news event, a photographer would take the pictures and handed over the exposed rolls of film to the newspaper's darkroom technicians who developed the negative, produced contact prints, and delivered these to the editor who decided which picture was to be used, how it was to be cropped, and how the finished print looked. Developing the film, waiting for it to dry, making the contact prints and finally producing a print took several hours.

Most newspapers and magazines have boarded up the darkrooms. The darkroom technicians are a dying breed. The digital cameras have all but eliminated the roll films, developing the negative, or making contact sheets. The finished product, the image, is instant. Cropping a picture and adjusting the colors and tones or making parts of a picture lighter or darker are all quickly accomplished with software such as Adobe Photoshop.

Digital camera and image correction software have not only popularized photography but also revolutionized photojournalism. Pavlik (2000) identifies four areas where technology has influenced journalism. These are (1) how journalists do their job and go about searching the web for the background information for a story; (2) the content of news, what passes for news, and the fading line between hard and soft news; (3) the structure of the newsroom and the news industry as jobs disappear with and cutbacks due to declining advertising revenues, and (4) the relationship between news organizations and their publics, especially how the consumers access the news.

The second notable change due to the technology is the shift from the word to the image. People no longer wish to read the news; they want to see it through photographs or moving images - with a minimum of words. The dominance of image over word seems global. A cursory glance at the newspapers from around the world, and the television channels catering to the Hispanic-Americans, the Asian Americans, and other foreign subgroups appear to be overloaded with split screens presenting an overwhelming amount of information through eye-catching infographics and colorful visuals, and a minimum of text scrolling across the bottom of the screen.

\section{Role of images in human history}

Humans' fascination with creating images of nature, tangible objects, and people dates to prehistoric times. Long before people were able to write, they were drawings pictures. These ancient works of art, or records of cave people's surroundings, were independent of their ability to draw, at least, from a contemporary perspective on draftsmanship. As the new tools, e.g., brushes and writing implements, were developed and new materials such as coal and colors became available, more people began expressing themselves by reproducing images of their world and joining the ranks of "artists." While the number of image-makers has grown with time, two factors continue to separate the skillful illustrator from the artist—skill 
and imagination. An illustrator needs the skills to draw; an artist must possess the imagination to alter the reality in an image. With skill, one can imitate; innovation depends on imagination.

Even when the early artists created images that resembled reality, there was no compulsion to reproduce the reality precisely. They were free to deviate from their perception of reality. Some did. People of science, however, needed to record images as realistically as possible and welcomed the devices such as camera obscura. A pinhole camera required not the artistic ability but a steady hand to make lifelike images maintaining accurate perspective.

Since cameras, lenses, and photochemical processes were discovered by men and women of science, cameras became the tools in the hands of architects, astronomers, biologists, botanists, and other scientists for recording their discoveries and observations. The photographs were the evidence. Even the early professional photographers specializing in still-life, nature, and portraits aimed to capture realistic slices of life and tried to reproduce reality as faithfully as possible.

Some of the early creative photographers such as Julia Margaret Cameron (1815-1879) and David Octavius Hill (1802-1870) created photographic images resembling the works of great painters. They aspired to the notion of image-as-art. However, the mainstream use of photography was not to replace or imitate high art but to keep records of important moments in one's life, i.e., retaining memories through pictures.

The mass production of inexpensive and easy-to-use box cameras by George Eastman (1854-1932), the founder of the Kodak Company, brought photography to the average American at an affordable price. Kodak, with its simple cameras and the slogan, "You press the button, we do the rest," industrialized photography.

Just as creative writing evolved from its commercial roots, creative individuals saw the artistic potential of photography - indeed, a camera could record a realistic image, but it could also distort reality or represent it in a different context. While it could represent reality, it could also misrepresent reality; it could be used to bend the truth, or even lie. Images could be factual, but they could just as easily be fiction.

\section{The contemporary role of photography}

The founder of the first Italian photographic agency in Milan, Grazia Neri claims that "the $20^{\text {th }}$ century can boast a significant precedent: that of having been photographed. Almost every historical event, scientific discovery, personage, the infinite natural disasters, the ill-doings of mankind and even his sentiments have been photographed" (2007). American essayist and filmmaker, Susan Sontag wrote, "[...] photographs alter and enlarge our notions of what is worth looking at and what we have a right to observe. [...] Photographed images do not seem to be statements about the world so much as pieces of it, miniatures of reality that anyone can make or acquire" (2000). 
Photographic images reinforce reality in three ways.

(1) Through supplying proof. We may doubt what we read or what we hear; we tend to believe if we can see a photographic proof.

(2) Through providing justification. A photographic image tells us that something does or did exist. If it's in a picture, it's there.

(3) Through establishing a visible reality.

For most people, the reality is what surrounds them; what they can see. Photographic images, according to Sontag (2000), seem to have "an innocent and therefore more accurate relation to visible reality." Most people when taking snapshots with their cell phone are collecting souvenirs from their reality. Professional photographers, such as Alfred Stieglitz and Paul Strand, captured their personal vision of the reality.

Capturing reality is the mission of photojournalists. But the perception of reality is a personal and subjective issue. A pen by itself is incapable of creating beautiful sonnets or vile obscenities. Its user, the writer, controls its output. One may pose a question: Has any author ever written the "whole" truth? The answer, of course, is: no. Nor has anyone written about all the truths of the universe. It is indeed absurd to expect that someone could accomplish such a task. It is neither possible nor necessary. A writer selects a topic and rejects others. Such a conscious decision - to include some elements and to exclude others - stems from personal biases and leads to subjectivity. No matter how hard a journalist/reporter may endeavor to assume an objective perspective, as soon as a topic is selected, many others are dropped. Though one may cover some aspects of a story truthfully and thoroughly, inevitably, some other aspects of the same story will be left out. Granted that time and space constraints limit the extent of depth and detail; these constraints are neither a justification for subjectivity nor an excuse for disregarding "the rest of the story."

Similarly, whether a camera tells the truth or distorts it will depend on the intention of the photographer who chooses to include some parts of the "reality" in his composition. Whatever is on the sides or behind the photographer, remains invisible. Whatever is behind opaque objects remains invisible. It is impossible for any camera to record the entire reality. Cameras are limited in their coverage by the focal length of their lenses. Telephoto lenses, for instance, compress the distance between the objects in the foreground and the background. The wide-angle lenses exaggerate the same distance and make the objects that are closer to the camera seem much larger than they are in relation to the objects in the middleground or the background. Simply changing the focal length can change the perception of reality.

Photojournalism emerged in the days when cameras used single glass-plates or rolls of film. With a glass plate, one could only take one picture. With rolls of film, the film size $(120,620,35 \mathrm{~mm})$, and picture formats $(6 \times 6 \mathrm{~cm}, 6 \times 9 \mathrm{~cm}$, $24 \times 36 \mathrm{~mm}$ ) cameras were limited as to how many pictures could be taken before reloading. Depending on the sensitivity of the film emulsion, pictures could have a grainer look, or different levels of contrast, producing dramatically different impressions of the same scene/subject. 
Professional photojournalists make conscious choices in selecting their cameras, lenses, film stocks, shutter speeds, lighting, filters, and processing conditions to create the desired look and feel. While looking through their viewfinders, photographers make conscious choices about what to include in the frame, what or who will be in the foreground, and what will be in the background. Photojournalists also pay close attention to their camera angels, i.e., is the camera looking up or looking down at the subject. High angle and low angle images produce different psychological emotions and impact on their viewers.

Pre-digital era photographers knew that through retouching, airbrushing, spotting, and dodging and burning, they could alter a photograph's impact. By choosing a certain grade of photographic paper, they could change the contrast in a picture - a high contrast image makes a different statement than if the same image is seen in low contrast.

Photographer, Jim Goldstein (2007) holds that nature and landscape photography should "accurately represent nature." He further argues that the purists may allow a minimum of editing in landscape and nature, however, the essence of photojournalism is grounded in accuracy in presenting or documenting the truth.

\section{Truth in journalism}

The problem begins with the insistence on "truth." Epistemologists from Aristotle to John Dewy (1859-1952) and Ludwig Wittgenstein (1889-1951) have wrestled with issues of mind/body, knower/known, ego/world, and being-in-itself/beingfor-itself. If, millennia later, we are no closer to an agreed upon definition of "truth," is it still necessary to consider the idea of truth in journalistic work? Is truth a constant or can it change over time? Is it even possible for a person to "tell the truth?" These are not only philosophical questions but everyday issues that the practicing photojournalists are continuously balancing. Clearly, these questions are rooted in ethics. To determine what the ethical norms are, Baumhart (1968) asked the business community, "What does ethics mean to you?" The responses fall into four categories.

1. Ethics has to do what my feelings tell me is right or wrong.

Following one's feelings do not lead to ethical behavior. A person following his or her feelings/emotions is likely to deviate from what is rational or ethical (Kahneman \& Tversky, 2000).

2. Ethics has to do with my religious beliefs.

Most religions set high ethical standards and provide motivation for ethical behavior. However, if ethics were limited to religion, then ethics would apply only to religious people. Obviously, ethics applies as much to a skeptic as to an ardent believer (Russell, 1927). 
3. Being ethical is doing what the law requires.

Not all laws incorporate ethical standards. Like feelings, laws can deviate from what is ethical. The apartheid laws of South Africa and the slavery laws of the United States are some famous examples of laws that deviated from what is ethical.

\section{Ethics consists of standards of behavior our society accepts.}

In any given society, most people accept and act according to ethical standards. But standards of behavior in a society can deviate from what is ethical. It is possible that an entire society or a large segment can become corrupt. No ethical standards could condone the behavior of members of the Ku Klux Klan, the confinement of the Japanese-Americans in camps during the WWII by the U.S. government; or the ill-treatment of the Jewish people by Nazi Germany. In all these cases, the respective societies accepted the unethical behaviors.

From these four groups of responses, we can at least determine what ethics is not. Velasquez et. al. (1992) suggest that ethics are two separate things. Firstly, it is the standards of rights and wrong that dictate what people ought to do in terms of rights, obligations, fairness, virtue, and benefits to society. These standards are supported by consistent and well-founded reasons. Secondly, ethics are the study and development of our ethical standards. Since we have seen that "our feelings, laws, and social norms can deviate from what is ethical," Velasquez et. al. (1987) warn that it is, necessary to monitor one's standards to ensure that they are reasonable and well-founded.

Looking at various cultures, one cannot fail to notice the differences in socially accepted practices, e.g. many societies condone infanticide, genocide, polygamy, racism, and torture. Anthropologists ask if there are any universal ethical codes, or are these culture-specific? The question of cultural norms and ethics has led to the concept of ethical relativism. It simply means that ethics is relative to the norms of a culture.

This concept is useful in dealing with ethics in photography. Photographs may be categorized as belonging to various genres: some represent nature, others depict fashion, and still others as product pictures, family pictures, war pictures, and finally, pictures representing social situations - a category that includes images of the aged, the homeless, the poor, the immigrants, and the socially undesirable.

At any given time, in any given culture, different ethical standards apply to different genres of photography. It is perfectly acceptable to apply makeup on a model for an advertisement for cosmetic products or adding fog and smoke to create a certain "feel" in product photography. It would be unacceptable to accentuate gray hair and wrinkles while photographing a homeless or a senior citizen. It would be utterly unacceptable to add smoke to a war-torn area. Thus, not all photographs are subject to the same criteria or ethical yardstick. Common sense, cultural norms, heuristics should be combined when evaluating photographs. 
Viewers realize and accept that print and TV advertisements use altered images. However, when a TV network reduced the waistline of its new anchorwoman, the alteration was unacceptable to the viewers. It is acceptable to arrange the actors on a stage for publicity pictures. No moral or ethical misdeeds are associated with staging publicity pictures for a new movie or a novel. It is quite a different matter when staging is involved in recording the images of the homeless or the wounded in the battlefield.

Echoing Bertrand Russell's position on ethics who posited that ethics was closely related to politics, and as such, an attempt to bring the collective desires of the leaders to bear upon individuals (1927), the structuralist Michel Foucault claimed that all ethical concepts were historically conditioned and the most important ones served the political function of controlling people rather than any purely cognitive purpose.

There is photographic evidence of manipulation of images during the times of Lenin and Stalin, as part of the Soviet efforts to aggrandize their leaders and delete certain facts from history books (King, 1997). In the United States, the celebrated documentary photographers, Walker Evans and Dorothea Lange, were commissioned by the Farm Security Administration (FSA) in the 1930s. Evans and Lange took scores of pictures of their "subjects until satisfied that they had gotten just the right look on film-the precise expression on the subject's face that supported their own notions about poverty, dignity, and exploitation" (Sontag, 1977). Their cameras were not recording the reality but creating a reality as the FSA wished to present. Presenting the marginalized in a negative light seems to be practiced globally. Italian photographer, Neri, claims that photography of local news fosters prejudice and racism. She offers the elderly and the immigrants as examples. "Older people are split into two categories: the rich and the marginalized. There are, however, a large number of dynamic and intelligent elderly people who do not belong to either of these sub-groups and who take an active part in life. Of these, there is practically no trace. Photographs of immigrants always allude to negative situations [...]. We never see images of positive integration" (Neri, 2007).

Deceptions in war photography and early recordings of war by such notable photographers as Roger Fenton in the Crimea, and Mathew Brady, leading a team of photographers to cover the American Civil War brought home views of war that, while horrific in some respects, also romanticized the war to desensitize the viewers to the ravages and brutality of war. The American poet, Oliver Wendell Holmes urged the readers of Atlanta Monthly to re-examine the photographs in these words:

Let him who wishes to know what war is look at this series of illustrations. These wrecks of manhood thrown together in careless heaps or ranged in ghastly rows for burial were alive but yesterday [...]. It gives us some conception of what a repulsive, brutal, sickening, hideous thing it is, this dashing together of two frantic mobs to which we give the name of armies. (Leggat, 2005) 
On the impact of war pictures, Susan Sontag, in a PBS interview with Bill Moyers (2003), recalled that she saw "the pictures taken in Dachau and Bergan Belson when the concentration camps were liberated in 1945. I was 12 years old when I saw these pictures. And I could say that my whole life is divided into before I saw those pictures and after." For many Americans during the 1960s, a similar dividing line was created by a sequence of images recorded by Abraham Zapruder during the assassination of President John F. Kennedy. Without those few frames, "the public would have passively accepted any prepackaged version of the event" (Neri, 2007).

In recent times, many Americans divide their lives based on the images that they saw of the fall of the World Trade Center Towers on September 11, 2001. A relatively small number of people witnessed the incident first hand. The rest of the country learned about it from the media images. It was the countless repetition of these images in the international press that has changed the worldview for millions around the globe, dividing the people on religious ideologies with the images of the tragic event. The Bush administration systematically exploited the same 9/11 images to mobilize a multinational support for attacking Iraq and orchestrating a regime change.

It is troublesome when images of atrocities of war are politically justified as moral and "right" actions. When political gains, national interests, and patriotism become justifications for manipulation, staging, and recreating reality for the benefit of the camera, the photographers become the mouthpiece of the prevailing political interest, and in so doing, both the politicians and the photojournalists are guilty of conspiring to hide the truth.

Using cameras as weapons of war is nothing new. As early as 1839, Daguerreotypes (one of the early processes for making photographic prints) were promoted as a means of recording the war at the battlefield by Joseph Louis GayLussac, and the photographs by James Robertson who covered the siege of Sebastopol was "a public relations exercise for the government of the day" (Leggat, 2005). Bradley and Fenton were the "official photographers" of the same engagement who routinely staged and arranged war scenes. Ray Rosenthal who is credited for the famous photograph, "Raising the Flag on Iwo Jima"- the picture of six soldiers raising the American flag was not a spontaneous snapshot. It was staged and attempted several times before the photographer and his assistant were satisfied (Renn, 2015). There have been "war photographers" who never actually saw any conflict. For instance, the Frenchman, Gaspard-Felix Tournachon, also known as Nadar, was asked by Napoleon III to photograph the troops from an air balloon. Nadar never got close to any military action. He only photographed the soldiers during the non-war time (McCouat, 2016), and Joseph Cundall and Robert Howlett, the two British photographers, whom Queen Victoria commissioned to produce a series of portraits of the soldiers, and the wounded, completed the "Crimean Braves" photographs before the troops set sail for the mission (Hershkowitz, 1993). 


\section{Conclusion}

A photograph, despite its genre, remains a personal matter as long it is seen only by the person who has taken it. As soon as a second person sees it, it becomes public. For this reason, a photographer is likely to be held answerable for every picture that he or she produces or alters using traditional pencil and brush, or computer software. In this regard, photographers are held accountable to a higher degree for their work than writers for their words. While words require a common agreement on meanings, images are independent of linguistic barriers. No words are needed to read and understand a picture. There's no misunderstanding or misreading a picture.

Regardless of the accepted standards of their times, those responsible for slavery in the United States of America, or these responsible for the treatment of the Jewish people in Nazi Germany, and those responsible for the apartheid in South Africa will always be held accountable, not only by their own countries, but globally, for their unethical and immoral conduct. The photographers taking pictures to justify those acts will also be judged according to the same ethical standards.

Let this be a warning to photographers (professionals and amateurs): one's work may become subject to not just local or culture-specific standards but universal criteria and international scrutiny. This is what happened to the American soldiers at Abu Gharib Prison that photographed the Iraqi prisoners ordered to undress and fall atop each other forming a heap of naked bodies. This is what happened to the Reuter photographer, Adnan Alhajj when he digitally added smoke and devastation to a Lebanese city after the Israeli bombing. This is what happened to Allan Detrich of the Toledo Blade who habitually added and removed elements from his pictures.

Digital technology has made photo editing easier, offering new options for recomposing and other alterations. For this, one cannot blame the technology. The question becomes "How much manipulation is acceptable?" Hanson (2017, p. 368) offers a yardstick by suggesting that a photographer address the following three issues:

(1) Follow the policies of the paper or the news organization. Do what is allowed.

(2) Let the viewer know that a picture has been altered.

(3) Don't do it if changing the picture will change the viewer's response.

Not unlike pencils and brushes, Adobe Photoshop and the like are instruments for correcting, enhancing, and improving the images. These are "innocent" tools - neither good nor bad. Image manipulation becomes an ethical issue when photographers either unwittingly or intentionally deviate from the accepted standards of their times.

Where does the responsibility fall? The present author holds that it clearly lies with the photographer. Taking pictures is a serious matter. It is serious in the sense that a photographer is choosing to speak in an international language in 
which there is neither room for naïveté, nor ignorance of other cultures' norms an excuse. In our global village of the new millennium, no visual dishonesty goes undetected for long.

Nor can the journalists and the news photographers have it both ways by claiming to be objective on the one hand, and on the other, justifying their inability to remain objective because of their personal biases. The journalists cannot continue to lean on subjectivity as a human weakness and insist on being taken as objective news reporters. They can't be both. If they want to inject their opinion and values into their stories, they should accept their roles as commentators. Some audience will accept their version of the truth while others may reject them as onesided speakers. Everyone has the right to express their opinion and should be free to do so. However, all opinions are not equal.

Similarly, photojournalists should approach their work in earnest and sincerity. They should decide whether they wish to be treated as news photographers or as illustrators. In a free and a democratic society, a photojournalist, not unlike Caesar's wife, should be above suspicion.

\section{References}

Baumhart, R. (1968). Ethics in business. New York: Holt, Rinehart and Winston.

Bill Moyers talks with Susan Sontag. (2003). NOW: Printable Transcript.

Davis, M. (2012, September 14). Faking photos: The ethics of photo manipulation. Center for Digital Ethics and Policy. https://www.digitalethics.org/essays/faking-photos-ethics-photo-manipulation

Foucault, M. (1969). The archaeology of knowledge. New York: Routledge.

Friedersdorf, C. (2013, June 3). Why does the American media get big stories wrong? The Atlantic. https://www.theatlantic.com/politics/archive/2013/ 06/why-does-the-american-media-get-big-stories-wrong/276454/

Goldstein, J. (2007). JMG Galleries - Ethics in photography: Career suicide by Photoshop. http://www.jmg-galleries.com/blog/2007/04/17/ethics-of-photo graphy-career-suicide-by-photoshop/

Hanson, R. (2017). Mass communication. Thousand Oaks, CA: Sage.

Hershkowitz, R. (1993). Cundall's and Howlett's Crimean heroes. History of Photography, 17(1), 120-121. doi: 10.1080/03087298.1993.10442603

Kahneman, D., \& Tversky, A. (2000). Choices, values, and frames. New York: Cambridge University Press.

King, D. (1997). The commissar vanishes: The falsification of photographs and art in Stalin's Russia. New York: Metropolitan Books.

Leggat, R. (2005). A history of photography: Photography of war. http://www. rleggat.com/photography/history/war.htm 
McCouat, P. (2016). The adventures of Nadar, photography, ballooning, invention, and impressionists. Journal of Art in Society. http://www.artinsociety. com/the-adventures-of-nadar-photography-ballooning-invention--the-im pres sionists.html

Neri, G. (2007). Ethics and photography. The Digital Journalist. http://www.digi taljournalist.org/issue0101/neri.htm

Pavlik, J. (2000). The impact of technology on journalism. Journalism Studies, 1(2), 229-237. doi: 10.1080/14616700050028226

Pullman, G. (2017, December 17). 10 photojournalists disciplined for doctoring pictures. Listverse.com. http://listverse.com/2017/12/27/10-photojournali sts-disciplined-for-doctoring-pictures/

Renn, M. (2015). The famous Iwo flag-raising: Iwo Jima revisited. History of Photography, 39(3), 253-262. doi: 10.1080/03087298.2014.995957

Russell, B. (1927). An outline of philosophy. London: George Allen \& Unwin.

Sontag, S. (1977). On photography. New York: Anchor Books.

Sontag, S. (2003). Regarding the pain of others. New York: Farrar, Straus \& Giroux.

Swift, A. (2016, September 14). American's trust in mass media sinks to new low. Gallup. https://news.gallup.com/poll/195542/americans-trust-mass-mediasinks-new-low.aspx

Unz, R. (2013). Our American Pravda. The American Conservative, May-June, 10-15.

Velasquez, M., Andre, C., Shanks, S. J., Meyer, M. (1987). What is ethics? Issues in Ethics, 1(1).

Velasquez, M., Andre, C., Shanks, S. J., Meyer, M. (1992). Ethical relativism. Issues in Ethics, 5(2). 